
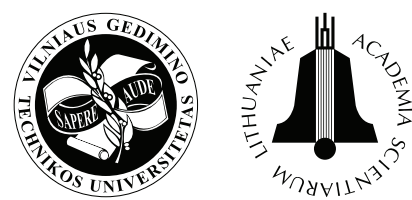

\title{
ANALYSIS OF THE ECOLOGICAL PARAMETERS OF THE DIESEL ENGINE POWERED WITH BIODIESEL FUEL CONTAINING METHYL ESTERS FROM CAMELINA SATIVA OIL
}

\author{
Sergejus Lebedevas ${ }^{1}$, Galina Lebedeva ${ }^{2}$, Violeta Makarevičiené $\dot{e}^{3}$, \\ Irina Kazanceva ${ }^{4}$, Kiril Kazancev ${ }^{5}$ \\ ${ }^{1}$ Dept of Marine Engineering, Klaipéda University Maritime Institute, \\ I. Kanto g. 7, LT-92123 Klaipeda, Lithuania \\ ${ }^{2}$ Dept of Computer Science, Faculty of Natural Sciences and Mathematics, Klaipeda University, \\ H. Manto g. 84, LT-92294 Klaipeda, Lithuania \\ 3, 4, ${ }^{5}$ Laboratory of Chemical and Biochemical Research for Environmental Technology, \\ Lithuanian University of Agriculture, Studentu g.11, LT-53361 Akademija, Kaunas r., Lithuania \\ E-mails: ${ }^{1}$ sergejus.lebedevas@ku.lt; ${ }^{2}$ galina@ik.ku.lt; 3,4,5agrotech@lzuu.lt
}

Received 16 November 2009; accepted 1 February 2010

\begin{abstract}
The article explores the possibilities of using fatty acid methyl esters derived from the oil of a new species of oily plant Camelina sativa not demanding on soil. The performed research on the physical and chemical properties of pure methyl esters from Camelina sativa show that biofuels do not meet requirements for the biodiesel fuel standard (LST EN 14214:2009) of a high iodine value and high content of linoleic acid methyl ester, so they must be mixed with methyl esters produced from pork lard the content of which in the mixture must be not less than $32 \%$. This article presents the results of tests on combustion emission obtained when three-cylinder diesel engine VALMET 320 DMG was fuelled with a mixture containing $30 \%$ of this new kind of fuel with fossil diesel fuel comparing with emissions obtained when the engine was fuelled with a fuel mixture containing $30 \%$ of conventional biodiesel fuel (rapeseed oil methyl esters) with fossil diesel fuel. The obtained results show that using both types of fuel, no significant differences in $\mathrm{CO}$ and $\mathrm{NO}_{\mathrm{x}}$ concentrations were observed throughout the tested load range. When operating on fuels containing methyl esters from Camelina sativa, $\mathrm{HC}$ emissions decreased by 10 to $12 \%$ and the smokeness of exhaust gas by 12 to $25 \%$.
\end{abstract}

Keywords: biodiesel fuel, Camelina sativa oil, diesel engine, ecological parameters.

\section{Introduction}

The European Commission encourages the use of biofuels in the transport sector. Directive 2003/30/EC (2003) states that the Member States of the EU should gradually increase the consumption of biofuels in transport and by 2010 , in total, $5.75 \%$ of transport fuels should be replaced by biofuels.

Producing and using biofuels has opened a new area in Lithuania as well as researches in this area (Matijošius and Sokolovskij 2009; Pukalskas et al. 2009; Raslavičius and Bazaras 2009; Lebedevas and Lebedeva 2009; Lingaitis and Pukalskas 2008a and 2008b; Butkus et al. 2007; Lebedevas et al. 2007; Raslavičius and Markšaitis 2007; Lebedevas et al. 2006a, 2006b).

However, despite the aspirations set out in the Directive, the development of using biofuels in the EU Member States is still insufficient. The actual average of EU biofuel consumption in the market is only about
$3.21 \%$ (2009) and is below the target - 5\% (EU-27 BioFuels Annual 2008). Meanwhile, the new EU documents 'An EU Strategy for Biofuels' (2006) and 'Biofuels in the European Union. Vision to 2030 and Beyond' (2006) provide for an increase in biofuel consumption to $15 \%$ by 2020 and up to $25 \%$ by 2030 . This will only be possible by increasing the production volumes and consumption of the first generation biofuels and via the introduction of producing the second generation biofuels providing for intensive industrial development after 2020.

In most cases, biodiesel fuel (75\% of biofuels in the market) and bioethanol (20\%) are used in the EU countries as the first generation biofuels (EU-27 BioFuels Annual 2008). However, the market of raw materials used in producing biodiesel fuel - rapeseed oil - is limited; therefore it is necessary to find new suitable raw materials for producing biodiesel fuel. Certain new kinds of vegetable oil that should have lower prices than 
the traditional rapeseed oil would increase the profitability of biodiesel fuel production and attractiveness to producers. In addition, it is necessary to find oil plants not demanding on soil and cultivated on barren lands not suitable for rapeseed cultivation because the potential of the latter process currently both in Lithuania and EU countries is approaching the limit on a lack of suitable land and crop rotation requirements. One of these oil plants recently attracted the interest of scientists is Camelina sativa grown as undersowing cereals in order to protect them from weeds without the use of mineral fertilizers and pesticides. The oil content of Camelina sativa seed is high and reaches about 43\% (Zubr 1997). However, the cultivation of this plant so far is for experimental purposes only and started in Lithuania relatively recently - in 2006. The properties of oil derived from this plant and the possibility of using it for producing fatty acid methyl esters are investigated. The preliminary results of foreign researchers show that due to the high content of polyunsaturated fatty acids, methyl esters from Camelina sativa oil could be used as biodiesel fuel only in a mixture with methyl esters from rapeseed oil (RME) (Mittelbach and Remschmidt 2004). Even better results might be obtained by inserting it into the mixtures of methyl esters from animal fat containing much saturated fatty acids.

In producing the new types of biodiesel fuel, it is necessary to evaluate not only its physical and chemical characteristics but also to carry out comparative performance tests on the engine assessing its motor and environmental performance in comparison with the properties of conventional biodiesel fuel. Literature and data about engine performance research on biodiesel fuel derived from Camelina sativa oil is relatively low and can be linked with recently launched experiments on cultivating and using this plant. Therefore, the aim of our work was to carry out comparative performance tests on the engine assessing the motor and ecological characteristics of fuels containing fatty acid methyl esters from Camelina sativa oil.

\section{Methodical Aspects of Researches}

\subsection{Object of Research}

The object of research was 3-cylinder diesel engine VALMET 320 DMG manufactured by AGCO SISU POWER which is a part of vessel diesel generator STAMFORD UC.M224C2 alternating the current of $28 \mathrm{~kW}$.

The main parameters of the diesel engine are given in Table 1.

Diesel engine design provides for its operation using fatty acid methyl esters (FAME) produced from rapeseed oil or cabbage oil.

During testing, the engine load has been ensured by gradually increasing electricity consumption produced by the diesel generator in the ship. With the diesel engine operating with all types of fuel, its load was increased from the modes close to idle to nominal modes $\left(P_{\text {enom }}\right): 5-10 \% P_{\text {enom }}, \sim 25 \% P_{\text {enom }}, \sim 55 \% P_{\text {enom }}$,
Table 1. The main parameters of diesel engine VALMET 320 DMG

\begin{tabular}{ll}
\hline \multicolumn{1}{c}{ Parameter } & \multicolumn{1}{c}{ Value } \\
\hline Number of cylinders & 3 \\
\hline Operational volume, $\mathrm{dm}^{3}$ & 3.3 \\
\hline Cylinder diameter, $\mathrm{mm}$ & 108 \\
\hline Stroke, $\mathrm{mm}$ & 120 \\
\hline Fuel injection method & Direct injection \\
\hline High pressure pump & Sectional Bosch \\
\hline Starting pressure of fuel injection, $\mathrm{MPa}$ & $23.5 \pm 0.5$ \\
\hline Nominal power $\left(P_{\text {enom }}\right), \mathrm{kW}$ & 30 \\
\hline Nominal rpm $\left(n_{\text {nom }}\right), \mathrm{min}^{-1}$ & 1500 \\
\hline
\end{tabular}

65-70\% $P_{\text {enom }}$ and $80-85 \% P_{\text {enom }}$ at nominal rotation speed, $n=1500 \mathrm{~min}^{-1}$. In order to ensure the repeatability of results and the stability control of engine technical condition at the beginning and end of the tests, they were carried out using fossil diesel fuel.

\subsection{Fuel Used for Researches}

Camelina sativa oil was obtained by mechanical pressing using Skeepsta Maskin Type 40A press (Sweden). Oil transesterification with methanol was carried out using laboratory equipment and applying a conventional method of rapeseed oil transesterification. Analytically pure methanol (Aldrich Chemical Company, Inc.) was used for transesterification and analytically pure $\mathrm{KOH}$ (Aldrich Chemical Company, Inc.) was used as a catalyst. Transesterification was carried out at two stages during the first of which, $11 \%$ of methanol was inserted into oil using $0.9 \% \mathrm{KOH}$ content while during the second stage $6 \%$ of methanol and $0.4 \mathrm{KOH}$ were used. After passing through each stage, glycerol fraction was separated and the esters obtained after the second stage had been over were washed using $10 \%$ of ester content with a $5 \%$ of phosphoric acid solution (Aldrich Chemical Company, Inc.). Following the process of washing with phosphoric acid, solution esters were washed twice using $10 \%$ of water. The traces of water from the esters were evaporated in a vacuum.

Pork lard methyl esters were produced from pork lard purchased from the market (Poland). After the evaporation of moisture, transesterification and the ester cleaning procedure of lard were carried out in the same way as the process of producing fatty acid methyl esters from Camelina sativa oil.

While preparing fuel for engine testing, in addition to the experimentally derived fatty acid methyl esters (FAME), fossil diesel fuel (D) purchased from the trade network and conforming to the requirements of LST EN 590 was used. According to the standard, it contained $5 \%$ (vol.) of rapeseed oil methyl esters (RME). Given the fact that pure biodiesel fuel still has no perspectives to be used as fuel in Lithuania for our tests, we took $30 \%$ 
(vol.) of biological origin fuel mixtures with fossil diesel fuel. This concentration was chosen taking into account a fact that foreign authors carried out tests on diesel engines (Lebedevas et al. 2006a, 2007) and found out that $30 \%$ of FAME mixture with D was of optimal concentration, in a view of improving diesel fuel economy and ecological indicators.

The quality indicators of fatty acid methyl esters and their mixtures were evaluated applying the procedures specified in the standard LST EN 14214:2009. The physical and chemical parameters of the tested fuels (methyl ester mixtures with fossil diesel fuel) were determined applying standard methods:

- density was defined following ISO 12185:1996;

- viscosity - ISO 3104:1994;

- cetane number - ISO 5165:1998;

- sulfur content - ISO 20846:2004;

- copper strip corrosion - ISO 2160:1998;

- flash point - ISO 3679:2004;

- ash content following ISO 6245:2001.

\subsection{Engine Testing}

The temperature mode of the diesel engine during the test was controlled using stationary devices for diesel generator on the control panel.

The power consumed by the generator was identified according to electrical current and voltage indications and was measured with portable device MINI AC/ DC CLAMP METER: current in the range of up to $40 \mathrm{~A}$ had the resolution of $0.01 \mathrm{~A}$ with the accuracy of $\pm 2.5 \%$; in measuring the voltage range of up to $400 \mathrm{~V}$, resolution was $0.1 \mathrm{~V}$ and accuracy made $\pm 1 \%$. On this basis, the accuracy of sensing power consumption was $\pm 3.5 \%$ and was rated as satisfactory for research operation.

The parameters of measurement devices for the harmful components of engine exhaust gas are given in Table 2.

\section{Results and Discussions}

\subsection{Physical and Chemical Parameters of Fuel}

The performed analysis on the quality of methyl esters from Camelina sativa oil (KSME) demonstrated that such methyl esters did not meet requirements for the standard LST EN 14214:2009 of the quality indicators of biodiesel fuel. These fuels have too high iodine value $143 \mathrm{~g} \mathrm{I}_{2} / 100 \mathrm{~g}$ while the standard specifies a maximum of $120 \mathrm{~g} \mathrm{I}_{2} / 100 \mathrm{~g}$. Because of the large content of polyunsaturated fatty acids in Camelina sativa oil, the resulting methyl esters have too high linolenic acid methyl esters content making $44.8 \%$, whereas the maximum limit under the standard is $12 \%$. For these reasons, pure KSME could not be used as fuel. On the contrary, pork lard has low unsaturated fatty acid content, and therefore the iodine value of pork lard methyl esters (KME) is low and makes $64.9 \mathrm{~g} \mathrm{I}_{2} / 100 \mathrm{~g}$. They don't contain linoleic acid methyl esters at all. The assumption was made that when mixing KSME and KME considering an appropriate ratio, biofuel meeting the requirements of standard LST EN 14214:2009 could be obtained. After testing, it was found that such mixtures had to contain $68 \%$ (vol.) of Camelina sativa oil and 32\% (vol.) of pork lard methyl esters. The quality indicators of such mixture and their compliance with the requirements of the standard are given in Table 3.

The data show that the mixture of KSME and KME meets quality requirements for biodiesel fuel, so in this composition it was used for producing fuel to test the engine. As mentioned above, this fuel included 30\% (vol.) of the fuel of biological origin which accounted for $5 \%$ of methyl esters from rapeseed oil (RME) mandatory included into mineral diesel fuel (D) in the marketing network. The composition of fuel used for comparative tests on the engine was as follows: fuel No. $1-70 \% \mathrm{D}$, $30 \%$ RME; fuel No. 2 - 70\% D, 17\% KSME, 8\% KME, $5 \%$ RME.

Quality indicators of such mixtures are presented in Table 4.

The presented data indicate that the mixtures containing KSME have characteristics slightly different from those containing RME and according to the main regulated characteristics of fuel for diesel engines, are in full compliance with the standard of biofuels. They have slightly higher viscosity and density and a lower Cetane number. Compared with pure D, it can be noted that the mixtures of biofuels also have higher density, viscosity, Cetane number and flash point.

Table 2. Parameters of measurement devices

\begin{tabular}{|c|c|c|c|c|c|c|c|c|}
\hline & & \multicolumn{7}{|c|}{ Measured components } \\
\hline & & $\mathrm{CO}$ & $\mathrm{CO}_{2}$ & $\mathrm{HC}$ & $\mathrm{O}_{2}$ & $\mathrm{NO}_{2}$ & $\mathrm{NO}$ & $\mathrm{NO}_{\mathrm{x}}$ \\
\hline \multirow{2}{*}{$\begin{array}{l}\text { Gas analyzer } \\
\text { HGA } 400\end{array}$} & Limits & $0-10 \%$ vol & $0-20 \%$ vol & $0-20000 \mathrm{ppm}$ & $0-22 \%$ vol & - & - & $0-5000 \mathrm{ppm}$ \\
\hline & Accuracy & $\pm 5 \%$ & $\pm 5 \%$ & $\pm 5 \%$ & $\pm 5 \%$ & - & - & $\pm 1 \mathrm{ppm}^{\star}$ \\
\hline \multirow{2}{*}{$\begin{array}{l}\text { Gas analyzer } \\
\text { TESTO } \\
330 \text { XL }\end{array}$} & Limits & 0-20000 ppm & $0-25 \%$ vol & - & $0-25 \%$ vol & $0-500 \mathrm{ppm}$ & $0-3000 \mathrm{ppm}$ & - \\
\hline & Accuracy & $\pm 5 \%$ & $\pm 0.3 \% \mathrm{vol}$ & - & $\pm 0.2 \% \mathrm{vol}$ & $\pm 5 \%$ & $\pm 5 \%$ & - \\
\hline \multirow{2}{*}{$\begin{array}{l}\text { Smoke meter } \\
\text { MDO-2 }\end{array}$} & Limits & \multicolumn{3}{|c|}{ Smokeness, $\% 0 \div 100$} & \multicolumn{4}{|c|}{ Coefficient of absorbance, $0-9.99 \mathrm{~m}^{-1}$} \\
\hline & Accuracy & \multicolumn{3}{|c|}{ $\pm 2 \%$} & \multicolumn{4}{|c|}{ $\pm 2 \%$} \\
\hline
\end{tabular}

\footnotetext{
* resolution
} 
Table 3. Quality indicators of the mixture containing $68 \%$ of Camelina sativa oil and $32 \%$ of methyl esters from pork lard and their compliance to the requirements of LST EN 14214:2009

\begin{tabular}{|c|c|c|c|c|}
\hline \multirow{2}{*}{ Parameter } & \multirow{2}{*}{ Unit } & \multicolumn{2}{|c|}{$\begin{array}{l}\text { Requirements } \\
\text { of LST EN } 14214\end{array}$} & \multirow{2}{*}{$\begin{array}{c}\text { Mixture of KSME } \\
\text { and KME }\end{array}$} \\
\hline & & $\min$ & $\max$ & \\
\hline Ester content & $\%$ (mass) & 96.5 & & 97.1 \\
\hline Density at $15^{\circ} \mathrm{C}$ & $\mathrm{kg} / \mathrm{m}^{3}$ & 860 & 900 & 865 \\
\hline Viscosity at $40^{\circ} \mathrm{C}$ & $\mathrm{mm}^{2} / \mathrm{s}$ & 3.50 & 5.00 & 4.8 \\
\hline Flash point & ${ }^{0} \mathrm{C}$ & 120 & - & 185 \\
\hline Sulfur content & $\mathrm{mg} / \mathrm{kg}$ & - & 10 & 18 \\
\hline Conradson carbon residue & $\%$ (mass) & - & 0.30 & 0.2 \\
\hline Cetane number & & 51.0 & - & 51.5 \\
\hline Sulfated ash content & $\%$ (mass) & - & 0.02 & 0.02 \\
\hline Water content & $\mathrm{mg} / \mathrm{kg}$ & - & 500 & 350 \\
\hline Total impurities & $\mathrm{mg} / \mathrm{kg}$ & - & 24 & 12 \\
\hline Oxidation stability at $110^{\circ} \mathrm{C}$ & $\mathrm{h}$ & 6.0 & - & 7.6 \\
\hline Acid value & $\mathrm{mg} \mathrm{KOH} / \mathrm{g}$ & - & 0.50 & 0.38 \\
\hline Iodine value & $\mathrm{g} \mathrm{I}_{2} / 100 \mathrm{~g}$ & - & 120 & 118 \\
\hline Linoleic acid methyl ester content & $\%$ & - & 12 & 12 \\
\hline $\begin{array}{l}\text { Polyunsaturated fatty acid methyl esters } \\
\text { content ( } \geq 4 \text { double bonds) }\end{array}$ & $\%$ (mass) & - & 1 & - \\
\hline Methanol content & $\%$ (mass) & - & 0.20 & 0.15 \\
\hline Monoglycerides & $\%$ (mass) & - & 0.80 & 0.48 \\
\hline Diglycerides & $\%$ (mass) & - & 0.20 & 0.1 \\
\hline Triglycerides & $\%$ (mass) & - & 0.20 & 0.1 \\
\hline Free glycerol & $\%$ (mass) & - & 0.02 & 0.05 \\
\hline Total glycerol & $\%$ (mass) & - & 0.25 & 0.30 \\
\hline Potassium $(\mathrm{K})$ content & $\mathrm{mg} / \mathrm{kg}$ & - & 5.0 & 4,5 \\
\hline Phosphorus content & $\mathrm{mg} / \mathrm{kg}$ & - & 10.0 & 8.0 \\
\hline
\end{tabular}

Table 4. Quality indicators of fuels

\begin{tabular}{lccccccc}
\hline \multicolumn{1}{c}{ Parameter } & Unit & Fuel No. 1 & Fuel No. 2 & D & RME & KSME & KME \\
\hline Ester content & $\%(\mathrm{vol})$ & 30 & 30 & - & 96.5 & 97.1 & 97.0 \\
\hline Density at $15^{\circ} \mathrm{C}$ & $\mathrm{kg} / \mathrm{m}^{3}$ & 848 & 849 & 840 & 890 & 864 & 866 \\
\hline Viscosity at $40^{\circ} \mathrm{C}$ & $\mathrm{mm}^{2} / \mathrm{s}$ & 2.97 & 3.2 & 2.5 & 4.7 & 3.7 & 5.4 \\
\hline Cetane number & & 49 & 48 & 46.0 & 51.6 & 51.3 & 51.6 \\
\hline Ash content & $\%(\mathrm{mass})$ & 0.007 & 0.01 & 0.01 & 0.02 & 0.02 & 0.01 \\
\hline Copper strip corrosion $\left(3\right.$ hours at $\left.5^{\circ} \mathrm{C}\right)$ & ${ }^{\circ} \mathrm{C}$ & 1 & 1 & 1 & 1 & 1 & 1 \\
\hline Flash point & ${ }^{\circ} \mathrm{C}$ & 101 & 103 & 68 & 185 & 180 & 190 \\
\hline
\end{tabular}




\subsection{Comparative Analysis of Environmental Indicators for the Diesel Engine}

Carbon monoxide. The nature of $\mathrm{CO}$ emissions changes when changing the engine load is equal for all tested fuels: minimum emission values are $\sim 150 \mathrm{ppm}$, reached at $60-70 \% P_{\text {enom }}$; at a lesser and higher load from $60-70 \% P_{\text {enom }}$, CO emission increases (see Fig. 1). The authors obtained a similar dependence of $\mathrm{CO}$ emission on $P_{e}$ was during $1 \mathrm{~A} 41$ and 2FL511 diesel engine tests on RME (Lebedevas et al. 2006b). Differently from those mentioned in the previous studies, a markedly less intensive growth of $\mathrm{CO}$ is close to the nominal one within the load modes. This could be explained by the improved operational process of engine 320 compared with the previously tested engines, especially with the obsolete model 1A41.

The level of $\mathrm{CO}$ emission in low and medium load modes are the same when using $\mathrm{D}$ and its mixtures containing only RME (D70/RME30) and the mixtures containing KSME (D70/RME5/KSME17/KME8). For the load exceeding 60 to $70 \% P_{\text {enom }}$, the consumption of biofuel with the types of methyl esters (B30) allows to reduce the emissions of CO by $\sim 20$ to $25 \%$ compared with fossil diesel fuel (D). Maximum CO emission was $\sim 250$ ppm recorded under low load conditions.

Nitrogen oxides. When increasing the load of the diesel engine, $\mathrm{NO}_{\mathrm{x}}$ emissions are monotonously growing from $170 \mathrm{ppm}$ to $\sim 1800 \mathrm{ppm}$ under nominal load conditions. A physical mechanism of $\mathrm{NO}_{\mathrm{x}}$ and $\mathrm{CO}$ formation in the engine cylinder is different (Kruggel 1989; Звонов 1981). Therefore, in most cases, the conversion of the diesel engine to work using different types of fuel is related to contrary changes in $\mathrm{CO}$ and $\mathrm{NO}_{\mathrm{x}}$ emissions (Lebedevas et al. 2006b; Chen et al. 2008; Al-Hasan and Al-Momany 2008; He et al. 2003). Similar results are obtained in the current tests. Unlike $\mathrm{CO}$ emission, the $\mathrm{NO}_{\mathrm{x}}$ emission of the diesel engine operating on both fuel containing $30 \%$ of RME, pure RME and fuel containing KSME increases by 7 to $8 \%$ in the nominal power modes, compared with pure fossil diesel fuel (see Fig. 2). With the diesel engine operating on D70/RME30 and D70/RME5/KSME17/KME8 fuels, nearly the same $\mathrm{NO}_{\mathrm{x}}$ emission was obtained within the entire range of load.

Hydrocarbons HC. The general positive characteristics of $\mathrm{HC}$ emission of all tested fuels features a strong increase in idle up to $30 \% P_{\text {enom }}$ modes, and further stabilization of their values under medium and nominal load conditions (see Fig. 3). HC emissions do not differ when the diesel engine operates on fossil diesel fuel and 30\% RME mixtures with D. The use of a new kind of diesel fuel D70/RME5/KSME17/KME8 based on Camelina sativa oil reduces HC emissions by $\sim 25$ to 30 ppm or by 10 to $12 \%$ within the main load range. This is one of the recorded advantages of the motor features of the new fuels.

Smokeness. The second advantage of fuel containing Camelina sativa oil methyl esters is reducing the smokeness of exhaust gas (SM) where the diesel engine operates on D70/RME5/KSME17/KME8. The reduction of SM content was recorded across the entire range of
$P_{e}$ and was equal to $12-25 \%$ ( $K$ factor values decrease to $0.025-0.05$ units at its maximum level of $\sim 0.35$ units) compared with D and D70/RME30 (see Fig. 4).

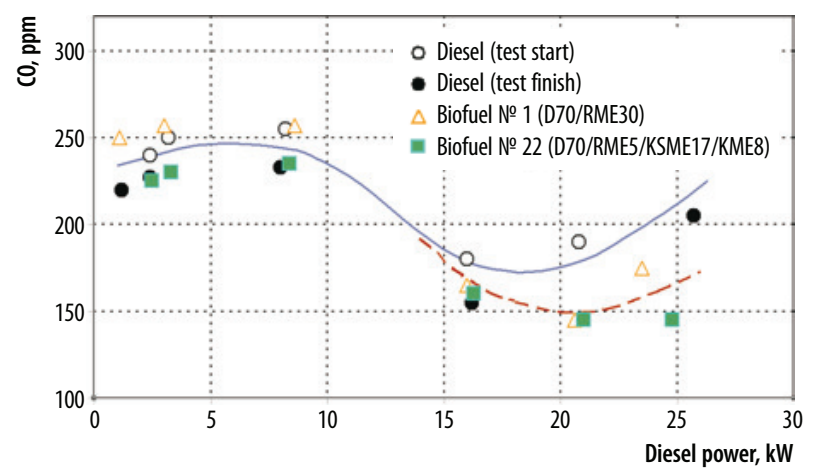

Fig. 1. Emissions of carbon monoxide from diesel engine VALMET 320 DMG operating on different types of fuels

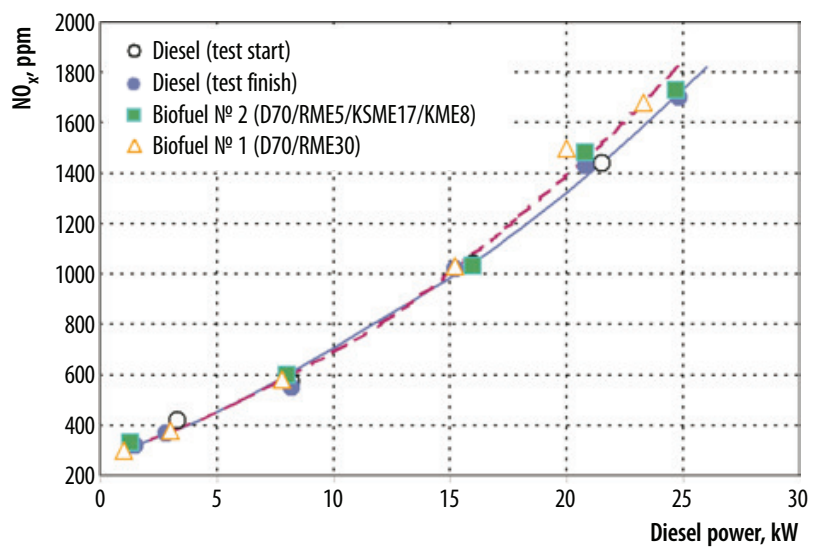

Fig. 2. Emissions of nitrogen oxide from diesel engine VALMET 320 DMGoperating on different types of fuels

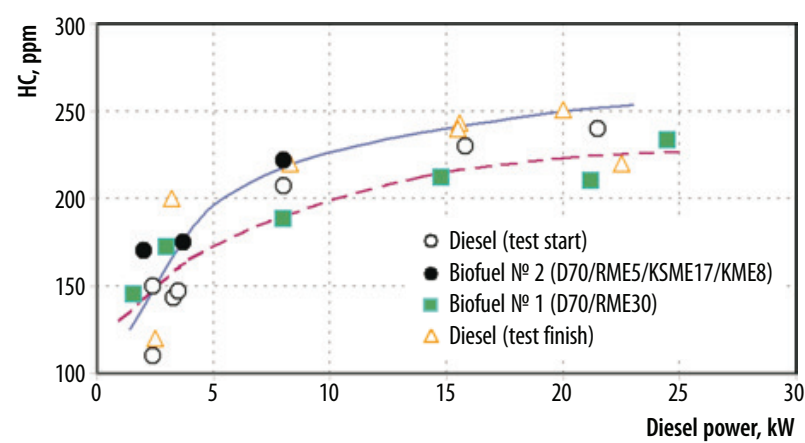

Fig. 3. Emissions of hydrocarbons from diesel engine VALMET 320 DMG operating on different types of fuels

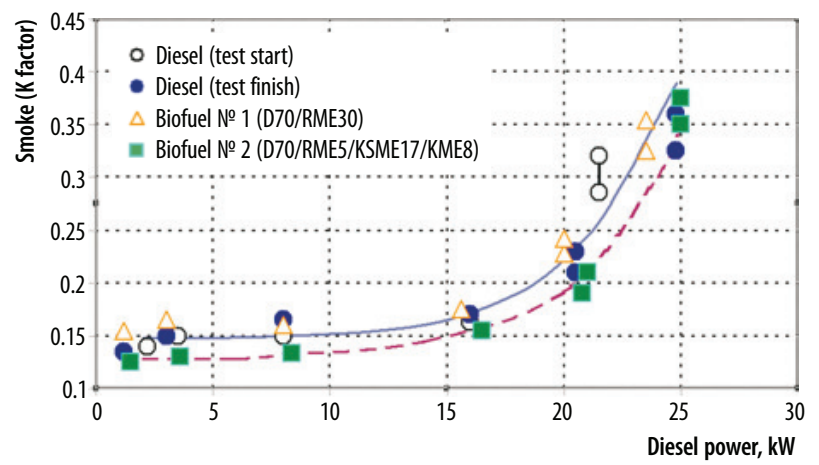

Fig. 4. Smokeness of exhaust gas from diesel engine VALMET 320 DMG operating on different types of fuels 


\section{Conclusions}

1. Methyl esters produced from pure Camelina sativa oil do not meet quality requirements applied for biodiesel fuel due to a high iodine value and the high content of linoleic acid methyl esters, and therefore cannot be directly used as fuel for diesel engines.

2. In order to use methyl esters from Camelina sativa oil in the diesel engine, they must be mixed with methyl esters from pork lard. A mixture containing methyl esters from Camelina sativa oil and pork lard complies with the requirements of LST EN 14214 at the ratio of 68:32 regarding the iodine value and the content of linolenic acid methyl esters.

3. The tests on operating diesel engine 320 manufactured by the company AGCO SISU POWER and used in the vessel, demonstrate favourable motor characteristics of the new type of biofuel containing methyl esters from Camelina sativa oil (KSME) in the mixture with methyl esters from pork lard (KME) at the determined optimum ratio of $68: 32$ :

- when compared with fuel containing $30 \%$ of RME in the mixture with fossil diesel fuel, the use of KSME-based biofuel (D70/RME5/KSME17/KME8) features the same $\mathrm{CO}$ and $\mathrm{NO}_{\mathrm{x}}$ emissions within the entire investigated range of loads from idle travel and makes up to $80 \% P_{\text {enom }}$, in comparison with fossil diesel fuel at the load greater than $60 \%$ of the nominal where $\mathrm{CO}$ emissions decrease from 20 to $25 \%$ and $\mathrm{NO}_{\mathrm{x}}$ increase from 7 to $8 \%$;

- the use of fuels D70/RME5/KSME17/KME8 reduced HC emissions by $\sim 10$ to $12 \%$ within the main load range and the smokeness of exhaust gas by 12 to $25 \%$ compared with D and D70/RME30.

4. Diesel fuel cost-saving and traction characteristics of the engines operating on KSME and based on the new types of biofuels will be tested on the motor test stand.

\section{Acknowledgments}

Research was carried out under the Eureka programme project 'E!4018 CAMELINA-BIOFUEL. The authors of the article deeply appreciate the assistance of the Agency for the Development of International Science and Technology.

\section{References}

Al-Hasan, M. I.; Al-Momany, M. 2008. The effect of iso-butanol-diesel blends on engine performance, Transport 23(4): 306-310. doi:10.3846/1648-4142.2008.23.306-310

An EU Strategy for Biofuels \{SEC(2006) 142\}. 2006. Communication from the Commission. Available from Internet: $<$ www.thepep.org/ClearingHouse/docfiles/EU.Strategy.for. Biofuels.pdf $>.29$ p.

Biofuels in the European Union. A Vision for 2030 and Beyond. 2006. Final draft report of the Biofuels Research Advisory Council. Available from Internet: <http://ec.europa.eu/research/energy/pdf/draft_vision_report_en.pdf $>.32 \mathrm{p}$.

Butkus, A.; Pukalskas, S.; Bogdanovičius, Z. 2007. The influence of turpentine additive on the ecological parameters of diesel engines, Transport 22(2): 80-82.
Chen, H.; Wang, J.; Shuai, S.; Chen, W. 2008. Study of oxygenated biomass fuel blends on a diesel engine, Fuel 87(15-16): 3462-3468. doi:10.1016/j.fuel.2008.04.034

Directive 2003/30/EC of the European Parliament and of the Council of 8 May 2003 on the Promotion of the Use of Biofuels or Other Renewable Fuels for Transport. Available from Internet: <http://ec.europa.eu/energy/res/legislation/doc/ biofuels/en_final.pdf $>$.

EU-27 Bio-Fuels Annual. 2008. GAIN Report - E48063. USDA Foreign Agricultural Service. Available from Internet: <www.fas.usda.gov/gainfiles/200806/146294845.pdf>. 27 p.

He, B.-Q.; Shuai, S.-J.; Wang, J.-X.; He, H. 2003. The effect of ethanol blended diesel fuels on emissions from a diesel engine, Atmospheric Environment 37(35): 4965-4971. doi:10.1016/j.atmosenv.2003.08.029

ISO 3104:1994. Petroleum products - Transparent and opaque liquids - Determination of kinematic viscosity and calculation of dynamic viscosity.

ISO 12185:1996. Crude petroleum and petroleum products Determination of density - Oscillating U-tube method.

ISO 2160:1998. Petroleum products - Corrosiveness to copperCopper strip test.

ISO 5165:1998. Petroleum products - Determination of the ignition quality of diesel fuels - Cetane engine method.

ISO 6245:2001. Petroleum products - Determination of ash.

ISO 3679:2004 Determination of flash point - Rapid equilibrium closed cup method

ISO 20846:2004. Petroleum products - Determination of sulfur content of automotive fuels - Ultraviolet fluorescence method.

Kruggel, O. 1989. Progress in the combustion technology of high performance diesel engines toward reduction of exhaust emissions without reduction of operation economy, in Proceedings of Baden-Wurttemberg Technology Conference. $14 \mathrm{p}$.

Lebedevas, S.; Lebedeva, G. 2009. The problems of using alcohol biofuel mixtures in the Lithuanian transport system, Transport 24(1): 58-65. doi:10.3846/1648-4142.2009.24.58-65

Lebedevas, S.; Vaicekauskas, A.; Lebedeva, G.; Janulis, P.; Makarevičienė, V. 2006a. Research into operational parameters of diesel engines running on RME biodiesel, Transport 21(4): 260-268.

Lebedevas, S.; Vaicekauskas, A.; Lebedeva, G.; Makarevičienè, V.; Janulis, P.; Kazancev, K. 2006b. Use of waste fats of animal and vegetable origin for the production of biodiesel fuel: quality, motor properties, and emissions of harmful components, Energy \& Fuels 20(5): 2274-2280. doi:10.1021/ef060145c

Lebedevas, S.; Vaicekauskas, A.; Suškov, P. 2007. Presumptions of effective operation of diesel engines running on RME biodiesel. Research on kinetics of combustion of RME biodiesel, Transport 22(2): 126-133.

Lingaitis, L. P.; Pukalskas, S. 2008a. Ecological aspects of using biological diesel oil in railway transport, Transport 23(2): 138-143. doi:10.3846/1648-4142.2008.23.138-143

Lingaitis, L. P.; Pukalskas, S. 2008b. The economic effect of using biological diesel oil on railway transport, Transport 23(4): 287-290. doi:10.3846/1648-4142.2008.23.287-290

LST EN 14214:2009. Automobiliniai degalai. Riebalų rūgščių metilesteriai (RRME), skirti dyzeliniams varikliams. Reikalavimai ir tyrimo metodai [Automotive fuels - Fatty acid methyl esters (FAME) for diesel engines - Requirements and test methods]. 
Matijošius, J.; Sokolovskij, E. 2009. Research into the quality of fuels and their biocomponents, Transport 24(3): 212-217. doi:10.3846/1648-4142.2009.24.212-217

Mittelbach, M.; Remschmidt, C. 2004. Biodiesel: A Comprehensive Handbook. Graz, Austria. 330 p.

Pukalskas, S.; Bogdanovičius, Z.; Sendžikienè, E.; Makarevičienè, V.; Janulis, P. 2009. The mixture of biobutanol and petrol for Otto engines, Transport 24(4): 301-307. doi:10.3846/1648-4142.2009.24.301-307

Raslavičius, L.; Bazaras, Ž. 2009. The analysis of the motor characteristics of D-RME-E fuel blend during onfield tests, Transport 24(3): 187-191.

doi:10.3846/1648-4142.2009.24.187-191

Raslavičius, L.; Markšaitis, D. 2007. Research into three-component biodiesel fuels combustion process using a single droplet technique, Transport 22(4): 312-315.

Zubr, J. 1997. Oil-seed crop: Camelina sativa, Industrial Crops and Products, Industrial Crops and Products 6(2): 113-119. doi:10.1016/S0926-6690(96)00203-8

Звонов, В. А. 1981. Токсичность двигателей внутреннего сгорания [Zvonov, V. A. Toxicity of the internal combustion engfine]. Москва: Машиностроение. 160 c. 